\title{
COVID-19 in a Patient with Accidental Drug-Induced Neutropenia
}

\author{
Pascal B Meyre ${ }^{1,2 *}$, Milos Radosavac ${ }^{1 *}$, Lukas Baumann ${ }^{1,}$ Rein Jan Piso ${ }^{1}$, Matthias Hoffmann ${ }^{1}$ \\ ${ }^{1}$ Department of Internal Medicine, Infectious Diseases and Hospital Epidemiology, Cantonal Hospital Olten, Switzerland \\ ${ }^{2}$ Cardiovascular Research Institute Basel, University Hospital Basel, University of Basel, Switzerland \\ *These authors contributed equally and are joint first authors
}

Received: 01/07/2020

Accepted: 07/07/2020

Published: $21 / 08 / 2020$

How to cite this article: Meyre PB, Radosavac M, Baumann L, Piso RJ, Hoffmann M. COVID-19 in a patient with accidental drug-induced neutropenia. EJCRIM 2020;7: doi:10.12890/2020_001848.

Conflicts of Interests: The Authors declare that there are no competing interests.

Acknowledgements: We thank this patient for participating in this case report

This article is licensed under a Commons Attribution Non-Commercial 4.0 License

\section{ABSTRACT}

Background: Coronavirus disease 2019 (COVID-19) presents with a wide range of illness severity, from asymptomatic disease to severe acute respiratory distress syndrome (ARDS). Immunosuppression is considered a risk factor for severe COVID-19, but there are only few reports on disease progression in immunocompromised patients.

Case Summary: We report the case of a 50-year-old patient with acute COVID-19 pneumonia, who had iatrogenic, clinically relevant bone marrow suppression due to accidental overdose with hydroxyurea, and decreased lung capacity due to a left-sided pneumonectomy 6 months earlier. Symptomatic treatment with oxygen supplementation and pulmonary physical therapy was initiated, and hydroxyurea was discontinued. Over 14 days, the patient's blood counts slowly recovered, and his clinical condition gradually improved, such that supplemental oxygen was no longer necessary and he could be discharged.

Discussion: A gradual increase in neutrophil and lymphocyte counts may be preferable to dampen a potentially detrimental immunological response triggered by severe acute respiratory syndrome coronavirus 2 (SARS-CoV-2). Whether patients with severe COVID-19 benefit from immunosuppressive therapy should be further evaluated.

\section{LEARNING POINTS}

- Acute respiratory distress syndrome is a serious complication in COVID-19 and appears to be triggered by a proinflammatory cytokine storm.

- Immunosuppression may avoid an immune hyper-response triggered by SARS-CoV-2.

\section{KEYWORDS}

COVID-19, neutropenia, pneumectomy, clinical course

\section{INTRODUCTION}

COVID-19 presents with a wide range of illness severity, from asymptomatic disease to severe ARDS ${ }^{[1]}$. Severe COVID-19 appears to be triggered by an exaggerated immune response mainly characterized by a proinflammatory cytokine storm ${ }^{[2]}$. While pre-existing immunodeficiency is considered a risk factor for severe illness, there are few reports on disease progression in immunocompromised patients. 


\section{CASE DESCRIPTION}

A 50-year old patient presented to our emergency department after referral by his general practitioner with a 1-week history of dry cough, malaise, fever and moderate dyspnoea. SARS-CoV-2 was identified by polymerase chain reaction (PCR) in a nasopharyngeal swab. The patient's medical history included a left-sided total pneumonectomy for curative treatment of adenocarcinoma 6 months previously, essential thrombocytosis for which the patient was treated with hydroxyurea, and deep vein thrombosis, for which the patient was on medication with rivaroxaban.

At presentation, the patient was afebrile $\left(37.5^{\circ} \mathrm{C}\right)$, with a slightly elevated blood pressure $(133 / 78 \mathrm{mmHg})$, normal heart rate $(84 \mathrm{bpm})$ and tachypnoea (30/min) (Table 1). Peripheral oxygen saturation was $98 \%$ on ambient air. A chest x-ray showed peri-bronchiolar infiltration in the right basal part of the lung and an opacified left hemithorax with a left-sided mediastinal shift due to pneumonectomy (Fig. 1, left panel). Laboratory testing revealed bicytopenia with anaemia (haemoglobin $97 \mathrm{~g} / \mathrm{l})$ and leukopenia $\left(1.2 \times 10^{9} / \mathrm{l}\right)$ with absolute neutropenia $\left(0.3 \times 10^{9} / \mathrm{l}\right)$, lymphopenia $\left(0.68 \times 10^{9} / \mathrm{l}\right)$ and normal thrombocytes $\left(211 \times 10^{9} / \mathrm{l}\right)$. C-reactive protein $(11.3 \mathrm{mg} / \mathrm{l})$, lactate dehydrogenase $(346$ $\mathrm{U} / \mathrm{I}$ ) and D-dimers $(657 \mu \mathrm{g} / \mathrm{l})$ were also elevated (Table 1). During further evaluation, it became evident that the patient had been taking far too high a dose of hydroxyurea (up to $2.5 \mathrm{~g} / \mathrm{day}$ ) due to a misunderstanding concerning his treatment regime. Therefore, it was concluded that the neutropenia was iatrogenic. Symptomatic treatment with hydration and pulmonary physical therapy was initiated, and hydroxyurea was discontinued. Filgrastim (granulocyte colony-stimulating factor) was not administered as we hypothesized that that rapid neutrophil reconstitution might trigger a more severe course of COVID-19 due to a more competent immune system.

\begin{tabular}{|c|c|c|c|c|c|c|c|c|c|}
\hline Measurements & Day 1 & Day 2 & Day 4 & Day 6 & Day 8 & Day 9 & $\begin{array}{l}\text { Day before } \\
\text { discharge }\end{array}$ & $\begin{array}{l}15 \text { Days after } \\
\text { discharge }\end{array}$ & Reference \\
\hline \multicolumn{10}{|l|}{ Vital signs } \\
\hline $\begin{array}{l}\text { Systolic blood pressure, } \\
\mathrm{mmHg}\end{array}$ & 133 & 102 & 117 & 127 & 123 & 121 & 111 & - & \\
\hline $\begin{array}{l}\text { Diastolic blood } \\
\text { pressure, } \mathrm{mmHg}\end{array}$ & 78 & 73 & 73 & 70 & 79 & 75 & 74 & - & \\
\hline Heart rate, bpm & 84 & 79 & 83 & 76 & 69 & 80 & 66 & - & \\
\hline Temperature, ${ }^{\circ} \mathrm{C}$ & 37.5 & 38.3 & 37.7 & 36.2 & 36.3 & 36.7 & 39.8 & - & \\
\hline Oxygen saturation, \%* & 98 & 97 & 96 & 94 & 96 & 97 & 96 & - & \\
\hline $\begin{array}{l}\text { Received supplemental } \\
\text { oxygen }\end{array}$ & $x$ & $x$ & $x$ & $x$ & - & - & - & - & \\
\hline \multicolumn{10}{|l|}{ Laboratory results } \\
\hline Haemoglobin, g/l & 97 & 88 & 98 & 90 & 84 & 86 & 83 & 121 & $137-165$ \\
\hline Leukocytes, $\times 109 / I$ & 1.2 & 1.0 & 1.8 & 2.5 & 3.2 & 3.6 & 3.5 & 7.0 & $3.9-9.5$ \\
\hline Platelets, $\times 109 / /$ & 211 & 172 & 159 & 166 & 180 & 205 & 232 & 687 & $140-360$ \\
\hline Lymphocytes, ×109/I & 0.68 & - & 0.62 & - & - & - & 1.20 & 1.86 & $1.13-3.00$ \\
\hline D-dimer, $n g / m l$ & 657 & - & - & 940 & 1227 & 1332 & 1351 & - & $<500$ \\
\hline Creatinine, $\mu \mathrm{mol} / \mathrm{I}$ & 57 & 53 & 41 & 44 & - & 49 & - & 73 & $64-104$ \\
\hline $\begin{array}{l}\text { Lactate } \\
\text { dehydrogenase, U/I }\end{array}$ & 346 & 284 & 338 & 367 & 285 & 340 & 220 & 250 & $125-220$ \\
\hline $\begin{array}{l}\text { C-reactive protein, } \\
\mathrm{mg} / \mathrm{l}\end{array}$ & 11.3 & 11.2 & 19.9 & 40.4 & 45.9 & 31.9 & 10.6 & 3.3 & $<5.1$ \\
\hline Procalcitonin, $\mathrm{ng} / \mathrm{ml}$ & - & - & - & - & - & 0.03 & - & - & $<0.1$ \\
\hline
\end{tabular}

Table 1. The patient's vital signs, laboratory measurements and radiography findings during hospitalization and at 15-day follow-up

*Measurements are without supplemental oxygen. 
Over the next 10 days, the patient's blood counts slowly recovered (leukocytes $3.5 \mathrm{~g} / \mathrm{l}$, lymphocytes $1.20 \mathrm{~g} / \mathrm{l}$, thrombocytes $232 \mathrm{~g} / \mathrm{l}$ ) and his clinical condition gradually improved such that supplemental oxygen could be halted on day 6. Given the possibility of a delayed immune response and the development of ARDS after the neutrophil count had recovered, the patient remained hospitalized for clinical observation and was discharged after 14 days. At a follow-up visit 15 days after discharge, the patient had normalized haemoglobin and leukocyte counts and chest computed tomography showed residual ubiquitous mild ground-glass opacifications (Fig. 1, right panel).
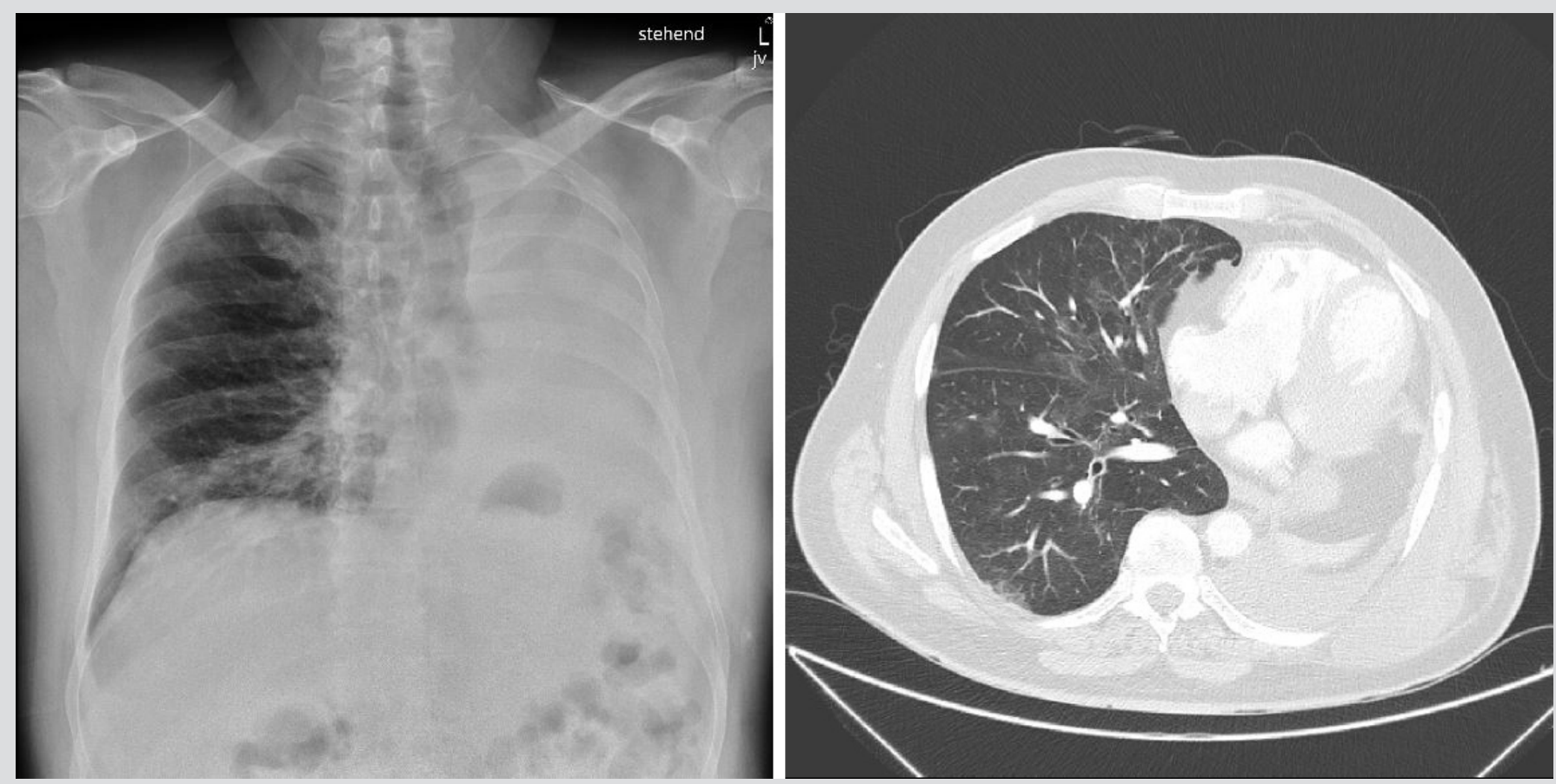

Figure 1. (Left panel) Chest x-ray performed at emergency department admission showing left-sided pneumonectomy and peri-bronchiolar infiltrate. (Right panel) Chest CT scan performed 15 days after discharge showing ubiquitous ground-glass opacifications characteristic for COVID-19

\section{DISCUSSION}

This patient presented with iatrogenic, clinically relevant neutrophil suppression (severe neutropenia) due to accidental overdosing with hydroxyurea, and lymphopenia which was lower than would be expected from viral disease alone. It has been thought that SARS-CoV-2 might trigger an excessive anti-viral immune response causing massive overproduction of inflammatory cytokines and tissue damage ${ }^{[3]}$. In severe COVID-19 disease, this overwhelming immune activation, known as a cytokine storm, is a major cause of severe disease and death regardless of pathogen burden ${ }^{[4]}$. High levels of cytokines from both T-helper-1 and T-helper- 2 cells have been found in patients affected by COVID-19 ${ }^{[3]}$. We therefore postulate that a gradual increase in the lymphocyte and neutrophil count instead of pharmacological stimulation may be preferable to avoid an additional immune hyper-response triggered by SARS-CoV-2.

While the patient's clinical course might have been good regardless of neutrophil or lymphocyte count, there is the possibility that the coincidental iatrogenic immunosuppression might have delayed or inhibited a potentially detrimental immunological response. In support of this hypothesis, preliminary results of the RECOVERY trial showed that administration of dexamethasone significantly reduces mortality rates in COVID-19 patients ${ }^{[5]}$.

Our patient was classified as having acute COVID-19 based on pulmonary infiltration at admission necessitating oxygen support shortly thereafter. A common strategy to treat acute infection in medication-induced neutropenia includes the administration of filgrastim to stimulate neutrophil production. However, we did not administer filgrastim because we suspected rapid neutrophil reconstitution might cause immune hyper-activation. We think this report may be helpful for other clinicians making decisions regarding patients in similar settings. To date, several clinical trials are testing the efficacy and safety of monoclonal antibodies against cytokines or their receptors (such as tocilizumab) in patients with COVID-19 pneumonia. 


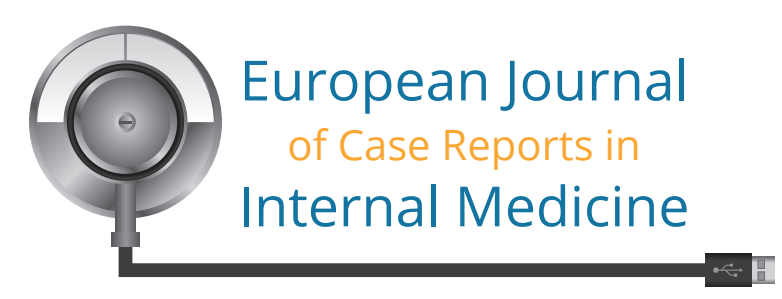

This case report from a single patient has several limitations, notably the lack of chest computed tomography at admission to assess initial lung involvement. Further reports of COVID-19 patients with neutropenia are required, as is further research into the pathophysiology of the immune response in severe COVID-19 to guide the development of treatment strategies for immune modulation.

\section{REFERENCES}

1. Richardson S, Hirsch JS, Narasimhan M, Crawford JM, McGinn T, Davidson KW, et al. Presenting characteristics, comorbidities, and outcomes among 5700 patients hospitalized with COVID-19 in the New York City area. JAMA 2020;323(20):2052-2059.

2. Mehta P, McAuley DF, Brown M, Sanchez E, Tattersall RS, Manson JJ. COVID-19: consider cytokine storm syndromes and immunosuppression. Lancet 2020;395(10229):10331034.

3. Huang C, Wang Y, Li X, Ren L, Zhao J, Hu Y, et al. Clinical features of patients infected with 2019 novel coronavirus in Wuhan, China. Lancet 2020;395(10223):497-506.

4. Wong CK, Lam CW, Wu AK, Ip WK, Lee NL, Chan IH, et al. Plasma inflammatory cytokines and chemokines in severe acute respiratory syndrome. Clin Exp Immunol 2004;136(1):95-103.

5. Horby P, Lim WS, Emberson J, Mafham M, Bell J, Linsell L, et al. Effect of dexamethasone in hospitalized patients with COVID-19-preliminary report. medRxiv 22 Jun 2020 (preprint). Available from: https://www.medrxiv.org/content/10.1101/2020.06.22.20137273v1.full.pdf. 